\title{
Ecologia da paisagem: mapeamento da vegetação da Reserva Biológica da Serra do Japi, Jundiaí, SP, Brasil
}

\author{
Eliana Cardoso-Leite ${ }^{1,5}$, Maria Inez Pagani² ${ }^{2}$ Reinaldo Monteiro ${ }^{3}$ e Diana Sarita Hamburger ${ }^{4}$
}

Recebido em 25/03/2002. Aceito em 01/09/2004

\begin{abstract}
RESUMO - (Ecologia da paisagem: mapeamento da vegetação da Reserva Biológica da Serra do Japi, Jundiaí, SP, Brasil). Foi realizado o mapeamento da vegetação da Reserva Biológica (REBIO) Municipal da Serra do Japi, Jundiaí, SP, por meio de fotointerpretação analógica, em escala 1:30.000. O mapa foi digitalizado e transferido para computador pelo sistema de informação geográfica (Idrisi) e posteriormente para o programa Corel Draw. Foram identificadas, mapeadas e descritas oito unidades de paisagem (UP) sendo três antrópicas (solo exposto, campo antrópico e reflorestamento homogêneo) e cinco naturais (floresta estacional semidecidual montana dossel uniforme - microfanerófitos; floresta estacional semidecidual montana dossel uniforme - mesofanerófitos; floresta estacional semidecidual montana dossel emergente; floresta estacional semidecidual aluvial dossel emergente e refúgio montano arbustivo). As unidades naturais somaram 98,46\% do total dos 2.071,20 ha da área, indicando que a Reserva vem cumprindo seu papel na preservação do ecossistema em questão. No entanto, como algumas unidades não tem expressiva representatividade na área, e como existe grande extensão de floresta no entorno da Reserva, sugere-se a ampliação e a transformação da mesma em uma unidade que contemple inclusive a visitação pública como forma de auxiliar no processo de conservação. Sugere-se que a área seja transformada em parque estadual, cujo nome poderia ser Parque Estadual da Serra do Japi.
\end{abstract}

Palavras-chave: mapeamento de vegetação, ecologia da paisagem, unidade de conservação, Serra do Japi

ABSTRACT - (Landscape ecology: vegetation map of the Reserva Biológica da Serra do Japi, Jundiaí, SP, Brazil). It was realized the vegetation map of the Reserva Biológica Municipal da Serra do Japi, at Jundiaí, São Paulo State, by analogical photointerpretation, on the scale 1:30.000. The map was digitized and changed to computer by the geographical information system - Idrisi, and then to the Corel Draw program. Eight landscape units, three anthropic - bare earth, anthropic prairie, homogeneous reforestation, and five natural units - mountainseasonal semideciduous forest with uniform canopy and microphanerophyts, mountain seasonal semideciduous forest with uniform canopy and mesophanerophyts, mountain seasonal semideciduous forest with emergent canopy, alluvial seasonal semideciduous forest with emergent canopy, and shrubby mountain refuges, were identified, mapped, and described. The natural units added $98,46 \%$ of the total area, showing that the Reserve is carrying out this role in the ecosystem conservation, but as some units are not significantly represented, and since of the large forest extension outside Reserve, it was offered the suggestion that the Reserve with the enlarged area be changed to another conservation unit-category and that contemplate the public visitation, to help in the conservation process. The conservation unit more appropriated is a Park, and could be denominated Parque Estadual da Serra do Japi.

Key words: vegetation map, landscape ecology, conservation unit, Serra do Japi

\section{Introdução}

A Serra do Japi pode ser considerada uma área prioritária para preservação, pois representa uma das últimas grandes áreas de floresta contínua do Estado de São Paulo e, embora já tenha sofrido alterações antrópicas, ainda representa a flora e a fauna ricas e exuberantes que existiam em grande parte da região sudeste do Brasil, antes da colonização (Morellato 1992). Além disso, está localizada em região altamente urbanizada - entre os municípios de São Paulo, Jundiaí e Campinas, aumentando seu risco de destruição. Desde 1983 a região da Serra do Japi é área tombada pelo CONDEPHAAT (São Paulo 1983). Em 1984, parte das áreas urbana e rural dos municípios de Jundiaí e Cabreúva foram decretadas Área de Proteção Ambiental - APA(São Paulo 1984), principalmente por englobar a região da Serra do Japi. Estas APAs foram criadas com o objetivo principal de preservar os recursos hídricos e a vegetação da Serra do Japi.

\footnotetext{
1 Universidade Estadual Paulista, Unidade Diferenciada de Registro, Av. Tamekichi Takano, 5, CEP 11900-000, Registro, SP, Brasil

2 Universidade Estadual Paulista, Instituto de Biociências, Departamento de Ecologia, CEP 13506-900, Rio Claro, SP, Brasil

3 Universidade Estadual Paulista, Instituto de Biociências, Departamento de Botânica, CEP 13506-900, Rio Claro, SP, Brasil

4 Faculdades SENAC de Educação Ambiental, SENAC, CEP 04311-000, São Paulo, SP, Brasil

5 Autor para correspondência: cardosoleite@registro.unesp.br, cardosoleite@yahoo.com.br
} 
Em 1991 foi criada a Reserva Biológica Municipal da Serra do Japi (Lei Municipal 3.672 de 10/01/1991), a qual foi regulamentada em 1992 (Lei Municipal 13.196 de 30/12/1992). A Reserva abrange 2.071,20 ha, dos quais estima-se que apenas $25 \%$ sejam de propriedade pública.

A UNESCO (1994) declarou a Reserva da Biosfera do Cinturão Verde da Cidade de São Paulo como parte integrante da Reserva da Biosfera da Mata Atlântica. Além da Floresta Ombrófila Densa (Mata Atlântica), representada pelo Parque Estadual da Serra do Mar, outras cinco áreas foram destacadas pela sua importância enquanto zona tampão ou zona de transição desta Reserva, e a Serra do Japi é uma delas.

A conservação da área é importante, pois atualmente as Unidades de Conservação Federais representam menos de 4\% do território nacional brasileiro e, no Estado de São Paulo, existem 85 Unidades de Conservação Estaduais, o que representa 3,14\% da área do Estado (Joly \& Bicudo 1999). Esta percentagem ainda é muito pequena.

A ecologia da paisagem é um instrumento útil para análise dos remanescentes de vegetação nativa existentes. Alguns autores definem a ecologia da paisagem como o estudo da distribuição dos elementos da paisagem, dos processos ecológicos que afetam os padrões, e das mudanças dos padrões ao longo do tempo (Forman \& Godron 1986). Naveh \& Lieberman (1984) descrevem o desenvolvimento histórico da ecologia da paisagem e afirmam que esta surgiu na Europa Central, na década de 1960, em decorrência de estudos da área de geografia humana e da ecologia holística. Mais recentemente, Metzger (1999) faz ampla análise bibliográfica sobre a estrutura da paisagem e a fragmentação. Bridgewater (1993) afirma que a ecologia da paisagem analisa o desenvolvimento e a dinâmica da heterogeneidade espacial, as interações espaciais e temporais e as mudanças na paisagem heterogênea, assim como as influências da heterogeneidade espacial nos processos bióticos e abióticos, e no manejo da paisagem.

Para Bertrand (1972) as unidades de paisagem podem ser divididas em seis grandezas. Nas categorias superiores tem-se a zona climática, o domínio morfoclimático e a região ou província geormorfológica. Dentre as categorias inferiores, o geossistema corresponde ao ecossistema (das ciências naturais), no entanto, incorpora o homem como parte dele e sua conseqüente interação com o meio, a geofácie (escala de $\mathrm{km}$ ou $\mathrm{m}$ ) está fortemente relacionada com diferenciações fisionômicas dentro de um geossistema, e o geótopo (escala de $\mathrm{m}$ a $\mathrm{dm}$ ) respresenta principalmente áreas relictuais ou endêmicas. Poderia-se dar como exemplo uma área na Serra do Mar em São Paulo, como pertencente a unidade de paisagem I (zona climática): zona de clima tropical; unidade de paisagem II (domínio morfo-climático): domínio tropical atlântico; unidade de paisagem III (região): região da província costeira; unidade de paisagem IV (geossistema): floresta ombrófila densa; unidade de paisagem V (geofácie): floresta ombrófila densa baixo montana ou floresta ombrófila densa montana; unidade de paisagem VI (geótopo): áreas de endemismos de algumas espécies de orquídeas.

Atualmente, a ecologia da paisagem tem sido utilizada para integrar diferentes disciplinas relacionadas à análise ambiental. No que se refere às escalas de trabalho utilizadas e à possibilidade de união entre diferentes ramos da ciência, a ecologia da paisagem tem-se mostrado muito interessante.

Recentemente alguns trabalhos já apresentam esta ponte de ligação, tanto entre escalas, quanto entre diferentes disciplinas. No Brasil, alguns estudos desta natureza foram realizados por Metzger \& Muller (1996), Metzger (1997), Pivello et al. (1998), Oliveira \& Porto (1999). Este trabalho representa mais uma contribuição neste sentido.

Vale ressaltar que a ecologia da paisagem incorpora a ação humana no ambiente, tanto pelo conceito de ecologia da paisagem, como pelo conceito de geossistema (Bertrand 1972). Desta forma, estudos de ecologia da paisagem podem apontar caminhos para o desenvolvimento sustentado e para um novo rumo na relação homem-natureza pois, como afirma Diegues (1994), a civilização atual está passando da proteção ingênua do mundo natural para a afirmação de uma nova relação entre homem-natureza.

Os objetivos deste trabalho foram: identificar, mapear, quantificar e caracterizar as Unidades de Paisagem (Bertrand 1972) ocorrentes na Serra do Japi e propor o melhor enquadramento da área dentre as categorias de Unidades de Conservação existentes no Brasil.

\section{Material e métodos}

A área de estudo constitui a Reserva Biológica Municipal da Serra do Japi no município de Jundiaí, SP (Fig. 1), com 2.071,20 ha, localizada entre as coordenadas $23^{\circ} 12^{\prime} / 23^{\circ} 21^{\prime}$ Sul e $46^{\circ} 30^{\prime} / 47^{\circ} 05^{\prime}$ Oeste, na província geomorfológica do Planalto Atlântico (Ponçano et al. 1981). Em sua maior parte, a Serra do 


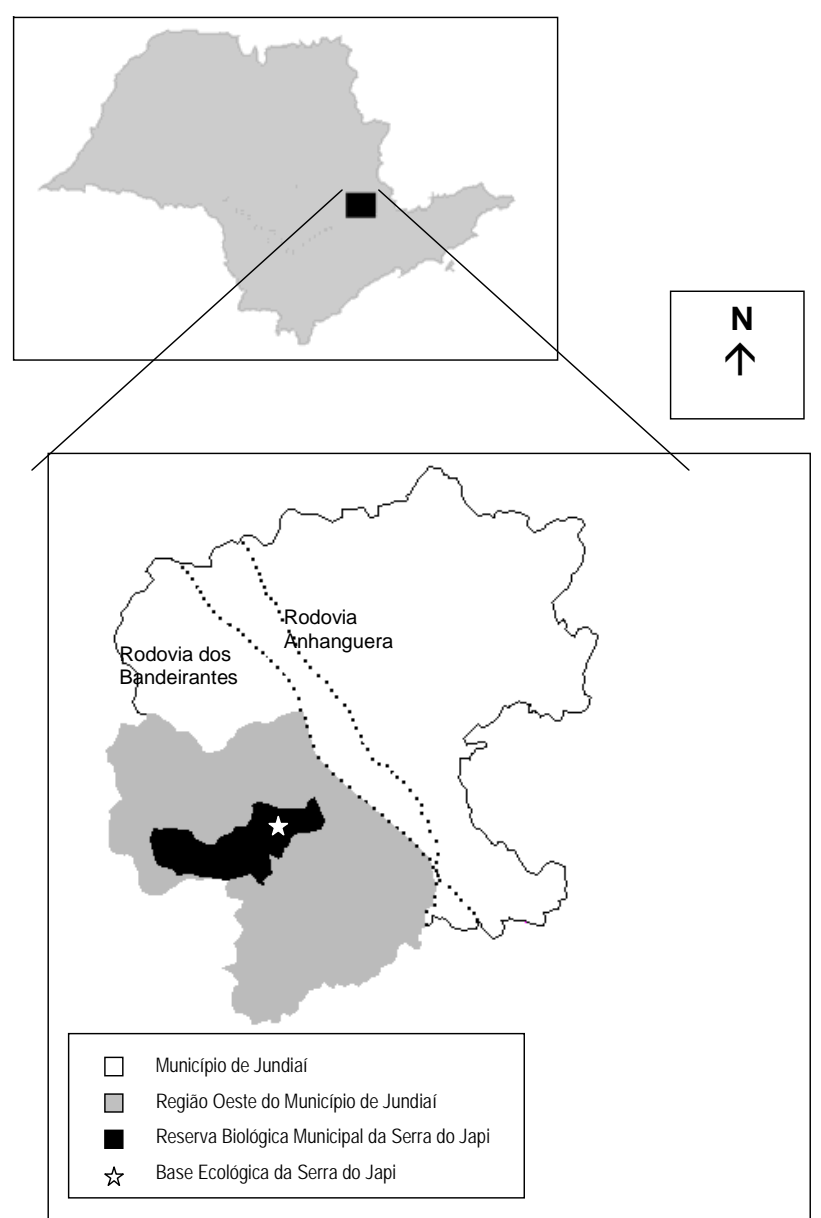

Figura 1. Localização do Município de Jundiaí no Estado de São Paulo, com destaque para a região oeste do Município, e para área de estudo, a Reserva Biológica Municipal da Serra do Japi. $\square=$ Município de Jundiaí, $\square=$ Região Oeste do Município de Jundiaí, - = Reserva Biológica da Serra do Japi, I = Base Ecológica da Serra do Japi.

Japi é constituída por rochas calcossilicatadas datadas do Proterozóico Inferior (Almeida et al. 1981). Os solos ocorrentes na Serra do Japi classificam-se como Latossolo Vermelho-Amarelo fase rasa, que é um tipo de solo encontrado no Planalto Atlântico entre as altitudes de 800 e 1.300 m, e Latossolo VermelhoAmarelo fase terraço, que também é ocorrente no Planalto Atlântico entre as altitudes de 550 e 750 m (Brasil 1960).

Estudos climáticos na região revelaram a existência de clima fortemente estacional, com uma estação quente e chuvosa e outra seca e fria (Pinto 1992). Os tipos de clima predominantes na área são o Cfa e Cfb (Setzer 1966). Segundo Veloso \& Góes-Filho (1982) e IBGE (Brasil 1992), a vegetação desta região é classificada como Floresta Estacional Semidecidual.

Das unidades de paisagem propostas por Bertrand (1972), pode-se identificar na área as seguintes: Zona
Tropical Atlântica (zona climática), Domínio Tropical Atlântico (domínio morfoclimático), Planalto Atlântico (região ou provínica geomorfológica), Floresta Estacional Semidecidual (geossistema). As categorias geofácie e geótopo foram identificadas e detalhadas no presente estudo, estando apresentadas nos resultados.

Inicialmente foi elaborado um mapeamento das unidades de paisagem (geofácies naturais e áreas de uso antrópico) por meio de fotointerpretação analógica realizada por intermédio de estereoscopia, segundo o método descrito por Anderson (1982), tendo como critérios principais a tonalidade de cinza, a textura e a forma destas unidades. Foram utilizadas fotos aéreas datadas de 1993, em escala 1:30.000.

Após a elaboração do mapa prévio, foi realizada a verificação em campo do mesmo por meio de visitas realizadas em toda a área, e comparação das fitofisionomias estudadas com o sistema de classificação da vegetação do IBGE (Brasil 1992), complementado pelo sistema de classificação local, baseado nas formas de vida proposto por Raunkiaer (1934).

Optou-se pela utilização destes dois sistemas pois o primeiro (Brasil 1992) é o sistema oficial e pode ser utilizado para qualquer região do país, mas que neste caso não permitiu o nível de detalhamento necessário, pois algumas unidades de paisagem reconhecidas no mapeamento apresentaram-se indistintas pela classificação do IBGE (Brasil 1992).

O sistema de Raunkiaer (1934) classifica indivíduos com gema de renovação situadas a $30 \mathrm{~cm}$ ou mais do solo como fanerófitos. O autor subdivide os fanerófitos em: nanofanerófitos - caule com menos de 2 m alt.; microfanerófitos - caule de 2-8 m alt.; mesofanerófitos - caule de 8-30 m alt.; megafanerófitos - caule com mais de 30 m alt. Com a utilização deste sistema, foi possível separar algumas unidades pela altura dos fanerófitos.

A mata ciliar (presente nos vales) e a mata das encostas sul/sudeste/sudoeste foram duas das sete unidades de paisagem previamente mapeadas. A delimitação entre estas unidades foi bastante trabalhosa. Após medições realizadas na fase de verificações em campo constatou-se que a largura média da mata ciliar na área estudada é de aproximadamente $25 \mathrm{~m}$. Como esta medida é muito próxima dos $30 \mathrm{~m}$, que é a faixa de mata protegida por lei (Brasil 1965; 2001) em rios com até 10 m larg., optou-se por usar esta última como medida para delimitação da mata ciliar, e representação da mesma no mapa final. Este critério arbitrário foi utilizado porque as diferenças fisionômicas, florísticas e estruturais 
(E. Cardoso-Leite, dados não publicados; Cardoso-Leite et al. 2002) entre estas duas formações foram nítidas, mas sua delimitação na foto não foi possível.

Das sete unidades mapeadas, quatro apresentaram cobertura florestal nativa e foram alvo de estudos mais detalhados com elaboração de perfis da vegetação e levantamento fitossociológico (Cardoso-Leite et al. 2002) pois constituem diferentes geofácies (fitofisionomias florestais) de ocorrência natural na região, além de predominarem na paisagem local. Como estes estudos mais detalhados foram realizados simultaneamente ao estudo de ecologia da paisagem seus resultados também complementam este trabalho.

Após a verificação em campo, elaborou-se o mapa final, o qual foi digitalizado e transferido para o Sistema de Informação Geográfica - Idrisi e, posteriormente, para o programa Corel Draw, para realização da arte final. O cálculo da área ocupada para cada unidade de paisagem foi realizado com o auxílio do programa Idrisi.

O mapa final foi elaborado em escala 1:30.000, ou seja, na escala original das fotos aéreas. Optou-se por manter esta escala, pois mesmo após exaustivo trabalho de campo é difícil espacializar e generalizar informações coletadas pontualmente. Portanto, a escala das fotos foi mantida como forma de assegurar a acuidade das informações.

Vale ressaltar que testes prévios foram realizados com imagens de satélite Landsat TM3, TM4, TM5, os quais não apresentaram o detalhamento exigido para os objetivos deste trabalho, portanto, optou-se pela utilização das fotos aéreas.

Foi realizada uma análise da REBIO no contexto da paisagem regional. Foram pesquisadas e analisadas Unidades de Conservação existentes na Serra do Japi. Estas Unidades foram discutidas sob o ponto de vista das restrições de uso do solo e das possibilidades de efetiva conservação.

Os resultados obtidos foram confrontados com os objetivos das Unidades de Conservação (Brasil 2000), discutindo o melhor enquadramento para a área dentre as categorias de Unidades de Conservação existentes no Brasil.

\section{Resultados e discussão}

A área de REBIO - Foram identificadas previamente sete unidades de paisagem (Tab. 1). As unidades um, dois e três foram interpretadas como resultantes da ação antrópica, e as unidades quatro, cinco, seis e sete foram interpretadas como diferentes fisionomias da vegetação natural.

Com a checagem de campo, verificou-se que as unidades um, dois, três, quatro, cinco e sete apresentavam identificação e localização corretas. No entanto, algumas vezes, no mapeamento prévio, as unidades dois e sete se confundiram, sendo posteriormente separadas com referências nas informações obtidas nas checagens de campo.

Verificou-se também que a unidade seis englobava duas unidades. Esta representava tanto a mata das vertentes $\mathrm{S} / \mathrm{SE}$ quanto as matas ciliares, também chamada de Floresta Aluvial. Observou-se que ambas apresentavam três estratos, ou seja, sub-bosque, dossel e indivíduos emergentes, porém a mata ciliar apresentava maior altura tanto do dossel quanto dos indivíduos emergentes, e maior espaçamento entre os mesmos.

A Tab. 2 apresenta as classes identificadas pela fotointerpretação, as correções feitas com a checagem de campo e a classificação destas formações segundo o IBGE (Brasil 1992), complementada pela classificação de Raunkiaer (1934).

Pela classificação do IBGE, as unidades quatro e cinco, respectivamente as formações dos topos de morros e das encostas N/NE/NW (norte/nordeste/ noroeste) reconhecidas no mapeamento, apresenta-

Tabela 1. Características observadas na fotos aéreas e sua chave de interpretação na Reserva Biológica Municipal da Serra do Japi, Jundiaí, SP, Brasil.

\begin{tabular}{ll}
\hline Textura/coloração/forma & Interpretação \\
\hline 1 - forma regular, textura lisa, coloração branca & Solo exposto \\
2 - forma regular, textura lisa a levemente rugosa, coloração cinza muito claro & Campo antrópico \\
3 - forma regular, textura lisa, coloração cinza muito escuro & Reflorestamento homogêneo \\
4 - forma irregular, textura lisa, coloração cinza médio & Mata dos topos de morros \\
5 - forma irregular, textura levemente rugosa, coloração cinza médio a escuro & Mata das vertentes norte/nordeste/noroeste dos \\
6 - forma irregular, textura rugosa a muito rugosa, coloração cinza muito escuro & morros, exceto os vales \\
7 - forma irregular, textura lisa a levemente rugosa, coloração cinza muito claro & Lajedos rochosos \\
\hline
\end{tabular}


Tabela 2. Unidades de paisagem (UP) na Reserva Biológica Municipal da Serra do Japi, Jundiaí, SP, Brasil, identificadas pela fotointerpretação, correções feitas pela checagem de campo e a classificação do IBGE (Brasil 1992) para estas formações, e nova nomenclatura, acrescentado a classificação de Raunkiaer (1934). Se = solo exposto, Ca = campo antrópico, Rh = reflorestamento homogêneo, Fmu-micro = floresta estacional semidecidual montanta, dossel uniforme- microfanerófitos, Fmu-meso = floresta estacional semidecidual montanta, dossel uniforme- mesofanerófitos, Fme = floresta estacional semidecidual montana, dossel emergente, Fae = floresta estacional semidecidual aluvial, dossel emergente, $\mathrm{Rmb}=$ refúgio montano arbustivo.

\begin{tabular}{|c|c|c|c|c|c|}
\hline Fotointerpretação & Verificação em campo & $\begin{array}{c}\text { Clas. IBGE + } \\
\text { Clas. Raunkiaer }\end{array}$ & $\begin{array}{c}\text { Nova numeração e } \\
\text { simbologia utilizada } \\
\text { para as UP }\end{array}$ & Área (ha) & Área (\%) \\
\hline 1 - Solo exposto & Solo exposto & & $1-$ Se & 4,03 & 0,19 \\
\hline 2 - Campo antrópico & Campo antrópico & & $2-\mathrm{Ca}$ & 21,00 & 1,01 \\
\hline 3 - Reflorestamento homogêneo & $\begin{array}{l}\text { Reflorestamento com Pinnus e/ou } \\
\text { Eucaliptus }\end{array}$ & & $3-\mathrm{Rh}$ & 7,02 & 0,34 \\
\hline 4 - Mata dos topos de morros & Mata de altitude & Fmu & 4 - Fmu-micro & 48,41 & 2,34 \\
\hline 5 - Mata das vertentes N/NE/NO & Floresta sem árvores emergentes & Fmu & 5 - Fmu-meso & 1051,17 & 50,74 \\
\hline \multirow[t]{2}{*}{6 - Mata das vertentes S/SE/SO } & Floresta com árvores emergentes & Fme & 6 - Fme & 579,71 & 27,98 \\
\hline & Mata Ciliar & Fae & 7 - Fae & 344,95 & 16,65 \\
\hline 7 - Lajedos rochosos & Vegetação xeromórfica & $\mathrm{Rmb}$ & $8-\mathrm{Rmb}$ & 15,31 & 0,74 \\
\hline
\end{tabular}

ram-se indistintas, sendo ambas classificadas como Fmu - floresta estacional semidecidual montana dossel uniforme.

Após a aplicação do sistema de classificação de Raunkiaer (1934), foi possível separar as unidades quatro e cinco pela altura dos indivíduos, que na unidade quatro é menor que $8 \mathrm{~m}$ e na unidade cinco, sempre maior. Assim, convencionou-se denominá-las, respectivamente, de Fmu-micro (floresta estacional semidecidual montana, dossel uniforme- microfanerófitos) e Fmu-meso (floresta estacional semidecidual montana, dossel uniforme- mesofanerófitos).

Analisando-se o mapa final (Fig. 2) pode-se verificar a existência de um único padrão de paisagem na Reserva Biológica da Serra do Japi, definido pela sucessão de morros recobertos por florestas nativas. Em geral, estes morros se estendem no sentido lesteoeste, produzindo vertentes com face de exposição voltadas para o norte/nordeste/noroeste e outras para o sul/sudeste/sudoeste. Este padrão único de paisagem contém os três elementos básicos da paisagem (Forman \& Godron 1986) que são matriz, manchas e corredores. O geossistema Floresta Estacional Semidecidual, com suas diferentes geofácies (unidades de paisagem quatro, cinco e seis) recobrem a maior parte da área, constituindo a matriz predominante (Tab. 2).

As áreas antrópicas como solo exposto, campo antrópico e reflorestamento homogêneo representam as manchas, que juntas somam apenas $1,54 \%$ da área da Reserva (Tab. 2).

Os corredores, que podem ser definidos como faixas de terra que diferem do seu entorno (Forman \& Godron 1986), são representados pelas trilhas e estradas que cortam a Reserva. A floresta aluvial (mata ciliar) mesmo não se destacando visualmente da matriz adjacente, representa um corredor natural pois conecta a área a outros remanescentes de vegetação existentes naquela região do Estado. Rodrigues \& Nave (2001) citando os trabalhos de Rizzini (1979), Pires \& Prance (1977) e Daly \& Prance (1989) afirmaram que as formações ciliares atuam como corredores ecológicos interligando diferentes unidades fitogeográficas e permitindo as extensões e o contacto florístico pretérito e atual destas unidades.

\section{Unidades de paisagem}

Unidades antrópicas - Entende-se por unidades antrópicas aquelas não recobertas por vegetação nativa (campo antrópico e reflorestamento homogêneo), ou que apresentam solo nu. Desta forma, as unidades um, dois e três foram interpretadas como unidades antrópicas.

Unidade um - Se - A proporção de área ocupada por solo exposto (Se), na REBIO é de apenas 0,19\%. Esta unidade está representada por áreas onde não existe qualquer tipo de cobertura vegetal. São áreas de construções e seus arredores, como quintais e estacionamentos. Não se constituem áreas de cultivo. Esta unidade está localizada em alguns sítios e chácaras de propriedade particular, e na área onde está localizada a Base Ecológica da Serra do Japi, local onde são recebidos visitantes e pesquisadores da Reserva. 


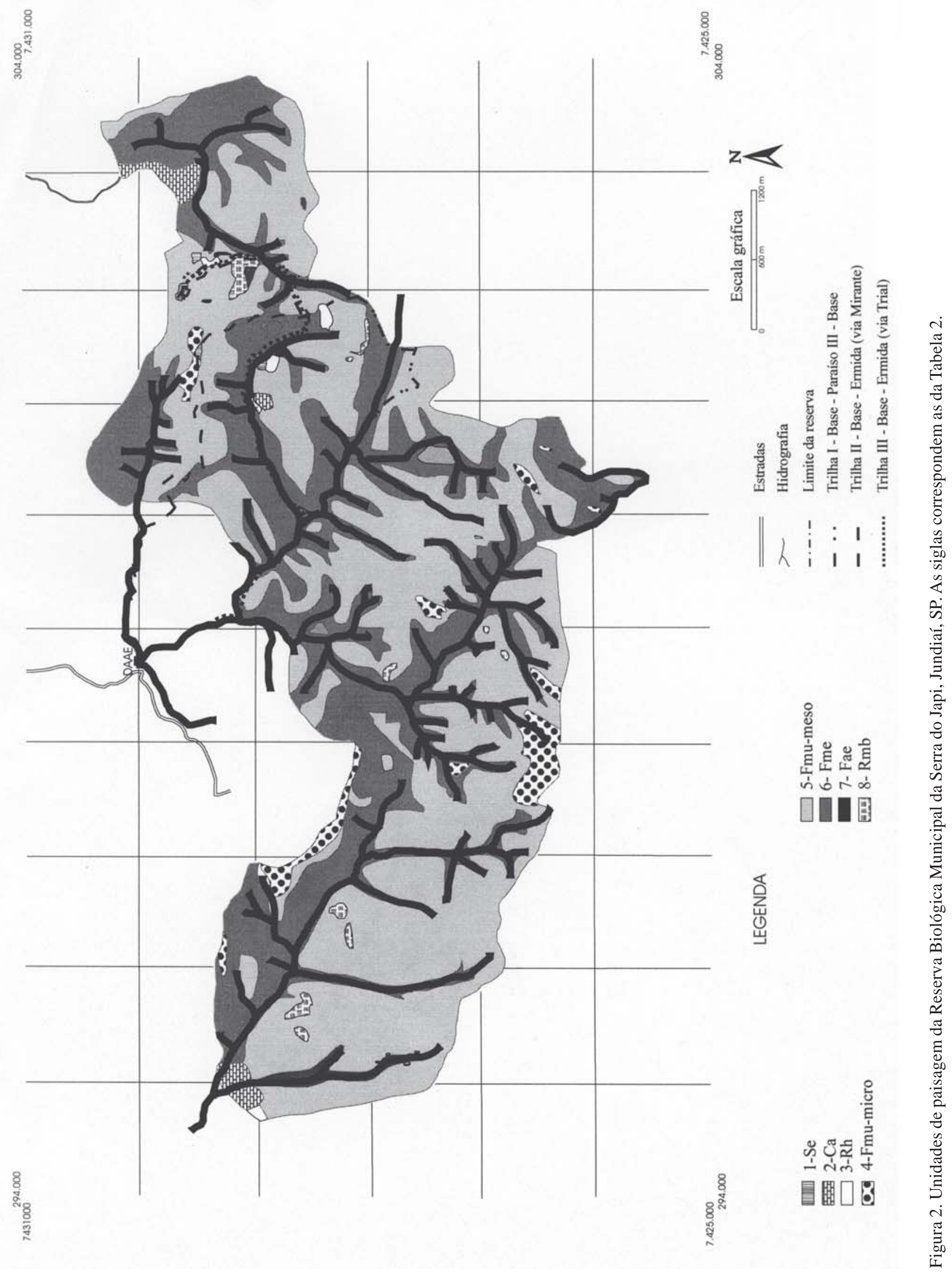


Unidade dois - $\mathrm{Ca}$ - Estes campos antrópicos (Ca), assim denominados por serem resultantes da ação humana, em geral estão recobertos por espécies invasoras de Poaceae. Estão localizados em propriedades particulares. No entanto, a área de ocupação dos mesmos é pequena, somando apenas 1,01\% da área total da Reserva.

Unidade três - Rh - A área representada por reflorestamento homogêneo (Rh) é de apenas 0,34\% do total. São florestas plantadas com espécies de Pinus sp. (Pinnaceae) ou Eucalyptus sp. (Myrtaceae). Como estas áreas são pouco representativas na REBIO, convencionou-se uni-las numa única unidade, denominada genericamente de reflorestamento homogêneo. Nas áreas recobertas por Pinus sp. não foi detectada presença de sub-bosque, no entanto nas áreas de Eucalyptus sp. o sub-bosque apresentou indivíduos jovens com altura entre 0,5-14 m, de diversas espécies nativas, como Alchornea triplinervea (Spreng.) Muell. Arg., Aspidosperma parvifolium Muell. Arg., Bathysa meridionalis Smith et Downs, Cabralea canjerana (Vell.) Mart., Casearia obliqua Spreng., Casearia sylvestris Sw., Cedrela fissilis Vell., Croton floribundus Spreng, Cupania vernalis Camb., Eugenia sp., Guapira opposita (Vell.) Reitz, Guateria nigrescens Mart., Inga sessilis (Vell.) Mart. ex Benth, Maytenus salicifolia Reissek, Mollinedia argyrogyna Perkins, Nectandra oppositifolia Ness., Psychotria sessilis (Vell.) Muell. Arg., Rapanea umbellata (Mart.) Mez. e Vernonia diffusa Less. Algumas destas espécies foram amostradas nas unidades com cobertura florestal nativa (Cardoso-Leite et al. 2002), dentre as espécies ecologicamente importantes, como Alchornea triplinervea na floresta de encosta face sul/sudeste/sudoeste (Fme), Bathysa meridionalis e Cabralea canjerana, na mata ciliar (Fae), Guapira opposita, na floresta de altitude (Fmumicro) e Maytenus salicifolia, na floresta de encosta face norte/nordeste/noroeste (Fmu-meso). Isto indica que, com o manejo adequado do Eucalyptus sp., ou seja, com sua retirada parcial e sucessiva ao longo do tempo, a floresta nativa pode se recuperar, uma vez que já existem indivíduos jovens de espécies nativas no sub-bosque.

Unidades naturais - Foram amostradas e mapeadas quatro unidades naturais distintas descritas a seguir.

Unidade quatro - Fmu-micro - Esta unidade está localizada nos topos dos morros (Fig. 2), onde o solo é muito raso e o horizonte A se assenta sobre a rocha. É representada por uma floresta composta por sub- bosque e dossel, com indivíduos arbóreos com pequeno diâmetro de caule. $\mathrm{O}$ dossel apresenta altura entre $5 \mathrm{~m}$ e $7 \mathrm{~m}$ e o sub-bosque, entre $2 \mathrm{~m}$ a $3 \mathrm{~m}$.

Dentre as geofácies naturais, esta constitui a unidade com menor representatividade na Reserva, ocupando 2,34\% da área da mesma (Tab. 2). Para saber se realmente todas as espécies aí presentes possuem tamanho de população suficiente dentro da área protegida, seria aconselhável um estudo específico de ecologia de populações na mesma. No entanto, a priori, recomenda-se uma expansão da área da Reserva, principalmente no sentido sudoeste da mesma (em direção ao município de Cabreúva), onde se tem grande área recoberta por esta geofácie. No levantamento fitossociológico realizado nesta geofácie (CardosoLeite et al. 2002) esta mostrou-se a mais diferenciada floristicamente em relação às demais formações florestais. As espécies que a caracterizaram estruturalmente foram: Guapira opposita (Vell.) Reitz., Machaerium nictitans Benth., Roupala brasiliensis Klotzch., Machaerium brasiliensis Vog., Callisthene minor Mart., Maytenus gonoclados Mart., Symplocos celastrinea Mart. e Ormosia minor (Vell.) Harms.

Unidade cinco - Fmu-meso - Esta unidade está localizada nos morros nas faces de exposição norte/ nordeste/noroeste (Fig. 2), e é representada por uma floresta com dossel de 9-11 m alt., e sub-bosque de 4-5 m alt. Os indivíduos arbóreos apresentam diâmetro de caule intermediário, quando comparados com os indivíduos arbóreos da Fme e da Fae. Esta unidade ocupa a maior proporção de área da REBIO ou seja, $50.74 \%$ (Tab. 2). A vegetação, por apresentar alto grau de deciduidade, confunde-se com uma floresta degradada principalmente no período de seca, que ocorre entre os meses de abril a setembro. No entanto esta é uma condição natural desta formação florestal. No levantamento fitossociológico realizado nesta geofácie (Cardoso-Leite et al. 2002) as espécies que caracterizaram estruturalmente esta fitofisionomia foram: Myrcia rostrata DC., Calycorectes acutatus Miq. Tol., Gochnatia polymorpha (Less.) Cabr., Machaerium villosum e Maytenus salicifolia.

Unidade seis - Fme - Esta unidade está localizada nos morros nas faces de exposição sul/sudeste/sudoeste (Fig. 2) e é representada por uma floresta com subbosque de altura entre 4-6 m, dossel com altura entre 10-14 m e indivíduos emergentes chegando a $19 \mathrm{~m}$ alt. Os indivíduos arbóreos apresentam diâmetro de tronco relativamente grande, quando comparados com aqueles 
presentes na Fmu-micro e na Fmu-meso. Depois da Fmu-meso, a Fme é a que mais se destaca em área ocupada na REBIO, ou seja, $27,98 \%$ da mesma (Tab. 2). Esta formação difere da primeira tanto fisionomicamente pela presença de indivíduos emergentes, quanto florística e estruturalmente (Cardoso-Leite et al. 2002). Também em relação à unidade de paisagem Fmu-meso, esta apresenta-se menos decídua, com aspecto verdejante mesmo na estação seca, indicando que as condições microclimáticas nesta face de exposição dos morros devem ser menos severas que na face norte/nordeste/noroeste. No levantamento fitossociológico realizado nesta geofácie (Cardoso-Leite et al. 2002) as espécies que caracterizaram estruturalmente esta fitofisionomia foram: Alchornea triplinervea, Laplacea semiserrata Cambess., Trichilia pallida Sw. e Persea pyrifolia Ness et Mart. ex Ness.

Unidade sete - Fae - Esta unidade está localizada nos vales úmidos e ao longo dos cursos d’água (Fig. 2), estando representada por uma floresta com subbosque de 3-6 m alt., dossel de 8-15 m, e indivíduos emergentes chegando até $22 \mathrm{~m}$ alt. Os indivíduos arbóreos apresesentam-se com diâmetro de tronco maior, quando comparados com os indivíduos das demais geofácies. A Fae (floresta estacional semidecidual aluvial) ocupa a terceira posição em área na Reserva, com 16,65\% do total (Tab. 2). Como exposto na metodologia, a delimitação desta formação baseou-se em critérios arbitrários, portanto a área apresentada para a mesma é uma aproximação, o que não invalida a discussão sobre sua importância. Neste estudo, a Fae está sendo tratada como uma geofácie do geossistema Floresta Estacional Semidecidual que recobre toda a região; no entanto em outras regiões onde não há predomínio de florestas e estas ocorrem associadas somente aos rios, devem ser tratadas como geossistemas (ou ecossistemas) diferenciados. Como discutido anteriormente, esta unidade apresenta-se como corredores na matriz adjacente, mesmo sem destacar-se visualmente na paisagem. No levantamento fitossociológico realizado nesta geofácie (Cardoso-Leite et al. 2002) as espécies que caracterizaram estruturalmente esta fitofisionomia foram: Bathysa meridionalis Smith \& Downs, Cabralea canjerana (Vell.) Mart., Cedrela fissilis Vell., Ocotea puberula (Rich.) Ness, Rapanea umbellata (Mart.) Mez.

Unidade oito - Rmb - Esta unidade, denominada de refúgio montano arbustivo (Rmb) ocorre sobre afloramentos rochosos e representa uma formação bastante pontual (Fig. 2), relativamente atípica na região. Dentre a taxonomia das unidades de paisagem, ela representa um geótopo, que se localiza dentro de uma das geofácies estudadas. Dentre as formações vegetacionais naturais, a menor área é representada pelo Rmb com apenas 0,74\% (Tab. 2), no entanto esta representa um geótopo que está incluído principalmente na Fmu-meso. Na checagem de campo, estas áreas foram visitadas e, além de representantes das famílias Bromeliaceae, Cactaceae e Orchidaceae bastante comuns nestes pontos, foram observadas algumas espécies lenhosas, como: Croton floribundus Spreng., Tibouchina granulosa Cogn., Alchornea triplinervea e Schinus terebinthifolius Raddi. Nestes pontos, a maioria dos indivíduos lenhosos não ultrapassa 1,5 m alt. Segundo Ab'Saber (1992), esta formação representa relictos de uma época geológica passada, ocorrida cerca de 13.000 anos, quando predominou na região um clima árido, depois da última glaciação. Nesta época, as florestas se retraíram e esta formação xeromórfica (Rmb) predominou na paisagem. O fato deste geótopo apresentar-se dentro da geofácie Fmumeso deve ter sido determinado pelas condições microclimáticas que nesta encosta são bastante restritivas, o que não permitiu o recobrimento destes pontos com florestas, após a retropicalização do clima.

Em estudo realizado anteriormente na área, Rodrigues \& Shepherd (1992) enfocaram a distribuição da vegetação ao longo do gradiente altitudinal na Serra. Os autores encontraram correlação entre altitude, características fisionômicas e florísticas da vegetação para os extremos de altitude, mas não encontraram correlação direta entre altitude e as características da vegetação para as áreas de altitude intermediária. No entanto, este estudo foi realizado ao longo de uma vertente com face de exposição oeste, o que acabou mascarando as características diferenciadas existentes entre as faces norte/nordeste/noroeste e sul/sudeste/ sudoeste. Como o levantamento foi pontual, não enfocando uma escala regional de estudo, os resultados não permitiram a compreensão da distribuição das diferentes fitofisionomias florestais (geofácies) na Serra, o que o presente estudo permitiu elucidar.

Estudos com ecologia da paisagem envolvendo mapeamento da vegetação em Unidades de Conservação não são muito freqüentes, principalmente em escalas de detalhe ou semidetalhe (1:50.000 ou maior). Estudos desta natureza foram realizados por Pivello et al. (1998) na Reserva de Cerrado Pé de Gigante, SP, e por Oliveira \& Porto (1999), no Parque 
Estadual do Delta do Jacuí, RS. Foram registrados, respectivamente, 100 e 52,6\% de cobertura vegetal nativa para estas áreas. Comparando os resultados do presente estudo com os acima citados pode-se dizer que a Reserva Biológica da Serra do Japi, assim como a Reserva de Cerrado Pé de Gigante (Pivello et al. 1998), vêm efetivamente cumprindo seu papel na conservação, pois apresentam quase que a totalidade da área recoberta por vegetação nativa, o que não acontece com o Parque Estadual de Jacuí (Oliveira \& Porto 1999). No entanto, a maior parte da área não recoberta por vegetação nativa neste Parque está ocupada por corpos d’água (27,9\%).

A REBIO no contexto regional da Serra do Japi - A Serra do Japi está localizada num contexto maior de áreas protegidas, fundamentais para a conservação dos remanescentes de Floresta Ombrófila Densa e Floresta Estacional Semidecidual, ainda existentes no sudeste do Brasil. Neste sentido vale a pena discutir a Reserva Biológica no contexto da paisagem regional e a conservação da Serra do Japi como um todo.

A REBIO está também inserida no perímetro das Áreas de Proteção Ambiental (APA) de Jundiaí e Cabreúva (São Paulo 1984). Analisando-se o Inventário Florestal do Estado de São Paulo (Kronka et al. 1993), pode-se observar que a vegetação nativa estende-se além da área da Reserva Biológica, atingindo toda a área das APA.

Através das fotos aéreas foi possível constatar também que em toda a região da Serra do Japi, encontra-se o geossistema Floresta Estacional com as geofácies encontradas na REBIO. Portanto, a Reserva representa uma pequena amostra da paisagem regional.

Na regulamentação das APAs de Jundiaí e Cabreúva (São Paulo 1998), o setor sudoeste do município de Jundiaí e o setor leste do município de Cabreúva (região da Serra do Japi), se enquadram na Zona de Vida Silvestre (ZVS) das APAs, ou seja, na zona de maior restrição de uso desta APA. Esta zona de preservação máxima inclui muitas áreas de reflorestamento e algumas culturas. Pode-se considerar que a mesma está de acordo com os objetivos de uma APA, que é conciliar o desenvolvimento econômico com a preservação.

No entanto, toda a área florestada da Serra do Japi, que está fora da REBIO, mesmo estando dentro da ZVS das APA não está sendo suficientemente protegida. As restrições de uso impostas pela ZVS das APA são: proibição de atividades minerárias, industriais e parcelamento do solo para fins urbanos; proibição de tratamento e disposição final de resíduos sólidos urbanos de qualquer natureza; proibição da expansão das áreas urbanas já existentes; o parcelamento do solo não pode resultar em terrenos inferiores a $20.000 \mathrm{~m}^{2}$; a implantação de empreendimentos depende de autorização da Secretaria do Meio Ambiente do Estado e $50 \%$ da área das propriedades devem ser destinadas à manutenção ou recomposição da mata nativa.

Desta forma, toda a área florestada (mata e capoeira) dos municípios de Jundiaí e Cabreúva que está dentro das APA e fora da REBIO não está sendo suficientemente preservada, pois em propriedades rurais é permitido o uso do solo para qualquer fim, inclusive com retirada da cobertura vegetal nativa, em até 50\% da área. Ou seja, pela legislação atual é autorizada a destruição de $50 \%$ de área de toda a floresta que não esteja dentro da Reserva. O decreto prevê, ainda, que dentro dos $50 \%$ de área destinados à manutenção da mata nativa, podem incluir-se as Áreas de Preservação Permanente (APP) e as Áreas de Reserva Florestal Legal já anteriormente preservadas pelo Código Florestal (Brasil 1965; 2001). Neste sentido, nem a decretação da área como APA e tampouco sua regulamentação representaram avanço para a conservação da área, no que se refere à sua proteção legal.

Certamente em poucos anos esta região estará quase que completamente desmatada, restando apenas aquelas APP, que já eram anteriormente protegidas, e que certamente constituem os $50 \%$ ou mais de área da Serra, pois o terreno é todo acidentado (declividade superior a $45^{\circ}$ ), existem muitos topos de morros e são inúmeras as nascentes, rios e riachos na Serra.

Além disto, a área do município de Cabreúva recoberta por florestas é mais extensa que a do município de Jundiaí e contém grandes extensões da Fmu-micro, que está pobremente representada dentro da Reserva Biológica Municipal (Tab. 2).

Sendo assim, considera-se que para a efetiva preservação deste ecossistema é necessária a criação de uma Unidade de Conservação intermunicipal. Uma vez que a região da Serra do Japi está localizada entre três grandes centros urbanos que são os municípios de Jundiaí, Campinas e São Paulo, existindo portanto uma grande demanda regional por áreas naturais que possam ser utilizadas pela população para lazer, recreação e turismo, e considerando-se que o conhecimento e o contato com áreas naturais constituem os principais meios para a sensibilização e conscientização da população em relação ao meio ambiente (Sharpe 1982), esta Unidade de Conservação deveria admitir a visitação e ter como objetivo o desenvolvimento de programas de uso público na área, proporcionando a 
possibilidade de contato dos visitantes com a natureza.

Portanto, sugere-se a criação de um Parque Estadual, cujo nome poderia ser Parque Estadual da Serra do Japi. Sugere-se que a administração do Parque seja estadual, primeiramente porque a área da Serra pertence a mais de um município e também porque acredita-se que o Estado possua mais recursos financeiros e humanos para realizá-lo.

A área proposta para o Parque está apresentada na Fig. 3. Os critérios utilizados para delimitação do mesmo foram: a presença de cobertura vegetal natural ou de ilhas de solo exposto ou reflorestamento que estejam circundados por formações naturais; presença de geofácies (dentro do geossistema Floresta Estacional Semidecidual) que não estivessem devidamente protegidas dentro da Reserva Biológica Municipal, como é o caso da Fmu-micro; a localização preferencial nos municípios de Jundiaí e Cabreúva, pois entre estes já existe um diálogo ambiental, tanto entre administrações públicas quanto entre setores da sociedade civil, em função da existência das APA.

Por meio dos resultados apresentados, pode-se concluir que a Reserva Biológica Municipal Serra do Japi vem cumprindo o seu papel na conservação de amostra significativa do ecossistema Floresta Estacional Semidecidual pois de seus 2.071,20 ha, $98,46 \%$ estão recobertos por este tipo de floresta.

No entanto, existem dentro da mesma, quatro unidades de paisagem representadas por fisionomias florestais diferenciadas que merecem, cada uma delas, ser tratadas como ecossistemas diferentes para fins de conservação, pois apresentam estrutura e composição também diferenciadas e algumas delas estão

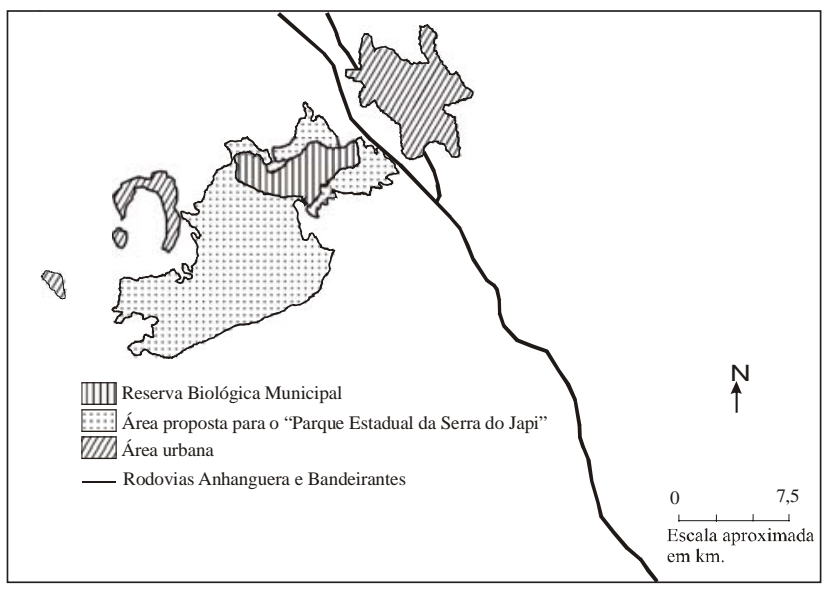

Figura 3. Região da Serra do Japi, evidenciando a área da Reserva Biológica Municipal da Serra do Japi, as áreas urbanas dos municípios de Jundiaí (leste) e Cabreúva (oeste) e a área proposta para o "Parque Estadual da Serra do Japi”. pobremente representadas dentro da Reserva, como é o caso da Fmu-micro, o que indica a necessidade de expansão da área da mesma.

Também quando analisada a área da Reserva em contexto regional, percebe-se que existe ainda grande extensão de área florestada além dos limites da mesma e que, pela legislação atual, não se encontra efetivamente protegida, tendo-se novamente a indicação de necessidade de aumento da área protegida.

Por outro lado, o fato da Unidade constituir uma Reserva Biológica, impede o acesso de visitantes, tanto da cidade e região quanto de outras localidades, o que se entende como um prejuízo para a sociedade e para a conservação, pois é necessário que as pessoas conheçam o local para tornarem-se aliadas na luta por sua preservação.

Os resultados deste trabalho permitiram concluir que existe a necessidade de ampliação da área desta Unidade de Conservação, sendo que o melhor enquadramento da mesma no Sistema Nacional de Unidades de Conservação (Brasil 2000) seria como Parque.

\section{Agradecimentos}

Os autores agradecem à Prefeitura Municipal de Jundiaí, pelo auxílio prestado ao desenvolvimento deste trabalho, através das Secretarias de Planejamento e Meio Ambiente, e de Educação, e especialmente aos funcionários da Base Ecológica da Serra do Japi, Valdete, Ronaldo, Zaíra e Sr. Lauro. Agradecem também aos técnicos do Departamento de Ecologia da Unesp-Rio Claro, Sérgio e Carlos, pelo auxílio nos trabalhos de campo.

\section{Referências bibliográficas}

Ab’Saber, A.N. 1992. A Serra do Japi, sua origem geomorfológica e a teoria dos refúgios. Pp. 12-23. In: L.P.C. Morellato (ed.). História Natural da Serra do Japi. Campinas, Editora da Unicamp, Fapesp.

Almeida, F.F.M.; Hasui, Y.; Ponçano, W.L.; Dantas, A.S.L.; Carneiro, C.D.R.; Melo, M.S. \& Bistrichi, C.A. 1981. Mapa geológico do Estado de São Paulo. IPT - Série Monografias, n. 6.

Anderson, P.S. 1982. Fundamentos para fotointerpretação. Rio de Janeiro, Sociedade Brasileira de Cartografia.

Bertrand, G. 1972. Paisagem e geografia física global- esboço metodológico. Caderno de Ciências da Terra - Instituto de Geografia - USP 13: 1-27.

Brasil. 1960. Ministério da Agricultura, Comissão de Solos. Levantamento de Reconhecimento dos Solos do Estado de São Paulo. Brasília, Boletim do Serviço Nacional de Pesquisas Agronômicas, n. 12. 
Brasil. 1965. Código florestal. Lei 4771, de 15 de setembro de 1965. Brasília, Diário Oficial da União, 16/09/1965.

Brasil. 1992. Manual Técnico da Vegetação Brasileira. Fundação Instituto Brasileiro de Geografia e EstatísticaIBGE. Rio de Janeiro, Secretaria do Orçamento e Coordenação da Presidência da República. Série Manuais Técnicos em Geociências.

Brasil. 2000. Ministério do Meio Ambiente. Lei 9.985, de 18 de julho de 2000. Brasília, Sistema Nacional de Unidades de Conservação - SNUC.

Brasil. 2001. Medida provisória 2166-67, de 24 de agosto de 2001. Altera e acresce dispositivos à Lei 4771, de 15 de setembro de 1965. In: www.planalto.gov.br/CCIVIL/ mpv2166-67.htm. Acessado em 6/10/2003.

Bridgewater, P.B. 1993. Landscape ecology, geographic information systems and nature conservation. Pp. 23-36. In: R. Haines-Young; D.R. Green \& S. Cousins (eds.). Landscape ecology and geographic information systems. New York, Taylor \& Francis Eds.

Cardoso-Leite, E.; Pagani, M.I.; Hamburger, D.S. \& Monteiro, R.R. 2002. Fitofisionomia, fitossociologia e conservação da vegetação na Reserva Biológica Municipal da Serra do Japi, Jundiaí, SP. Naturalia 27: 165-200.

Diegues, A.C.S. 1994. O mito moderno da natureza intocada. NUPAUB, São Paulo, Universidade de São Paulo.

Forman, R.T.T. \& Godron, M. 1986. Landscape ecology. New York, John Wiley.

Joly, C.A. \& Bicudo, C.E.M. (orgs.). 1999. Biodiversidade do Estado de São Paulo, Brasil: síntese do conhecimento ao final do século XX, v.7. São Paulo, Fapesp.

Kronka, J.N.F.; Matsukuma, C.K.; Nalon, M.A.; del Cali, I.H.; Rossi, M.; Mattos, I.F.A.; Shin-Ike, M.S. \& Pontinhas, A.A.S. 1993. Inventário Florestal do Estado de São Paulo. São Paulo, Secretaria do Meio Ambiente do Estado de São Paulo, Coordenadoria de Informações Tecnológicas, Documentação e Pesquisa, Instituto Florestal.

Metzger, J.P. \& Muller, E. 1996. Characterinzing he complexity of landscape boundaries by remote sensing. Landscape Ecology 11: 65-77.

Metzger, J.P. 1997. Relationship between landscape structure and tree species diversity in tropical forests of SouthEast Brazil. Landscape Urban Planning 37: 29-35.

Metzger, J.P. 1999. Estrutura da Paisagem e Fragmentação: análise Bibliográfica. Anais da Academia Brasileira de Ciências 71(3-I): 445-463.

Morellato, L.P.C. 1992. Introdução. Pp. 8-11. In: L.P.C. Morellato (ed.). História Natural da Serra do Japi. Campinas, Editora da Unicamp, Fapesp.

Naveh, Z. \& Lieberman, A.S. 1984. Landscape ecology: theory and application. New York, Springer.
Oliveira, M.L.A.A. \& Porto, M.L. 1999. Ecologia da paisagem do Parque Estadual do Delta do Jacuí, Rio Grande do Sul, Brasil: mapa da cobertura do solo e vegetação, a partir de imagem do LANDSAT TM5. Iheringia, Série Botânica 53: 89-144.

Pinto, H.S. 1992. Clima da Serra do Japi. Pp. 30-38. In: L.P.C. Morellato (ed.). História Natural da Serra do Japi. Campinas, Editora da Unicamp, Fapesp.

Pivello, V.R.; Bitencourt, M.D.; Mantovani, W.; Mesquita Junior, H.N.; Batalha, M.A. \& Shida, C.N. 1998. Proposta de zoneamento ecológico para a Reserva de Cerrado Péde-Gigante (Santa Rita do Passa Quatro, SP). Brazilian Journal of Ecology 2: 108-118.

Ponçano, W.T.; Carneiro, C.D.R.; Bistrichi, C.A; Almeida, F.F.M. \& Prandini, F.L. 1981. Mapa geomorfológico do Estado de São Paulo. IPT - Série Monografias n. 5.

Raunkiaer, C. 1934. The life forms of plants and statistical plant geography. Oxford, Clarendon.

Rodrigues, R.R. \& Shepherd, G.J. 1992. Análise da variação estrutural e fisionômica da vegetação e características edáficas, num gradiente altitudinal na Serra do Japi. Pp. 64-96. In: Morellato, L.P.C. (ed.). História Natural da Serra do Japi. Campinas, Editora da Unicamp, Fapesp.

Rodrigues, R.R. \& Nave, A.G. (eds.). 2001. Heterogeneidade florística das matas ciliares. In: R.R. Rodrigues \& H.F. Leitão-Filho. Matas ciliares - conservação e recuperação. São Paulo, Editora da Universidade de São Paulo/Fapesp.

São Paulo (Estado). 1983. Ato de tombamento das Serras do Japi, Guaxinduva e Jaguacoara. Diário Oficial do Estado de São Paulo de 12/03/83. São Paulo, Imesp, Secretaria do Estado da Cultura.

São Paulo (Estado). 1984. Lei Estadual 4095, de 12/06/84, cria as Áreas de Proteção Ambiental de Jundiaí e Cabreúva. São Paulo, Imesp, Secretaria do Estado do Meio Ambiente.

São Paulo (Estado). 1998. Decreto 43.284, de 3 de julho de 1998, regulamenta as APAs de Jundiaí e Cabreúva. São Paulo, Imesp, Secretaria do Estado do Meio Ambiente.

Setzer, J. 1966. Atlas climático e ecológico do Estado de São Paulo. São Paulo, Comissão Interestadual da Bacia Paraná-Uruguai e Centrais Elétricas de Estado de São Paulo.

Sharpe, G. W. 1982. Interpreting the Environment. London, Wiley \& Sons.

Unesco. 1994. Réserve de la Biosphère de la Ceinture verte de la ville de São Paulo comme partie intégrante de la Réserve de la Biosphère de la Forêt Atlantique. Paris, Unesco-MAB.

Veloso, H.P. \& Góes-Filho, L. 1982. Fitogeografia brasileira: uma classificação fisionômica-ecológica da vegetação neotropical. Boletim Técnico. Projeto Radambrasil. Série Vegetação. Salvador, Brasil - Ministério das Minas e Energia. 